\title{
A Study on Azygos System of Veins and Venous Aneurysm
}

\author{
Narayanan.G. , Aruna. S , Balaji T.K., Kannan.G., Venkateshgobi.V. \\ Sivaraj institute of medical sciences, Salem \\ Indra Gandhi institute of medical sciences, Puducherry. \\ Chettinad Hospital and Research institute. \\ Sivaraj Homoeopathic medical college and hospital. \\ Sivaraj institute of medical sciences
}

\begin{abstract}
Introduction: The azygos system of veins drains most of the posterior abdominal and thoracic wall. It also receives mediastinal, bronchial and oesophageal veins. The azygos vein serves as an important channel of communication between superior and inferior venacava. The vein also communicates with the vertebral venous plexus. Materials \& methods: The present study on azygos system of vein was carried out in the Department of Anatomy, SIMS. A total of 32 cadavers irrespective of age and sex were used for this study. The azygos vein was traced right from its formation. Its course in the posterior mediastinum and termination into superior venacava, any variation in the origin, termination and its tributaries such as hemi azygos and accessory hemi azygos vein was carefully observed and photographed. Results: Variation in the drainage pattern of hemi azygos and accessory hemi azygos were observed in seven specimens of which three specimens show a two way drainage of hemi azygos vein and accessory hemi azygos vein into azygos and left brachiocephalic vein. Conclusion: Knowledge of such variations exhibiting different drainage pattern is significant during mediastinal surgeries as it may poses a potential source of haemorrhage,and aneurysm of azygos systems of veins. Such abnormal communications may also lead to misinterpretation of CT and MRI findings of posterior mediastinum.
\end{abstract}

\section{Introduction}

Variations of azygos system of veins are usually associated with other congenital anomalies, especially cardiac anomalies. According to recent data, the incidence of this variation is $0.6-2.0 \%$ in individuals with congenital cardiac malformations and less than $0.3 \%$ in individuals without any variations or anomalies (Trubac et al, 2002). Presence of this vascular variation without any other anomalies causes no clinically evident problems. Such variations are found only during radiological examination or surgical procedures of posterior mediastinum. This variation can cause venous insufficiency of lower limbs with a potential thromboembolic disease. These venous anomalies may be mistaken for mediastinal mass or lymphadenopathy.

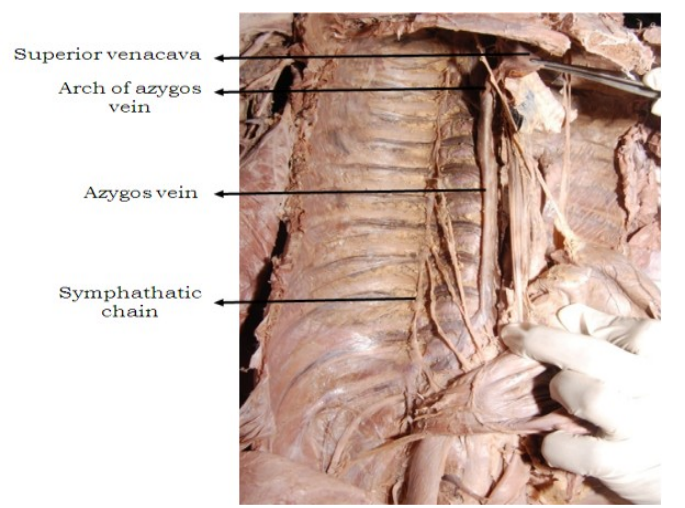

Fig 1: Azygos vein draining into superior vena cava

\section{Azygos System Of Veins}

The word azygos means "unpaired". Azygos system of veins drain the thoracic wall above the lumbar region and communicate with venacaval system in front and vertebral venous plexus behind.

FORMATION Azygos vein is formed by the union of right subcostal vein and right ascending lumbar vein at the level of renal vein or below the level of renal vein. It may arise as a single vein from the inferior venacava (lumbar azygos) and ascend in front of lumbar vertebrae After its formation, the azygos vein ascends upwards in front of upper lumbar vertebrae and then it pierces the right crus of diaphragm or passes through the aortic 
opening of diaphragm. Related to right side of cisterna chyli, passes forwards on the right side of the body of the twelfth thoracic vertebra behind the right crus of the diaphragm, then it ascends upwards to reach the posterior mediastinum. At the level of fourth thoracic vertebra it arches forwards above the root of the right lung and ends in the superior venacava just before the latter pierces the pericardium.During intra uterine development of embryo, Venous system are derived from three major veins such as,Cardinal veins - from the body wall Umbilical veins - from the placenta Vitelline veins - from the yolk sac

\section{Materials And Methods}

The present study was carried out in the Department of Anatomy, Sivaraj Homoeopathic medical college and Hospital. A total number of 32 cadavers including 14 female cadavers were utilized for the present study. To study the azygos system of veins, the posterior mediastinum was approached from the front of chest wall in a step by step manner. The pectoral muscles were removed from the anterior thoracic wall, the ribs were cut along the mid axillary line, and the anterior part of thoracic cage was opened as a single flap with its sternal attachment intact. The lung was removed by placing a ligature at the root. The origin, course, tributaries and termination of azygos, hemi azygos and accessory hemi azygos veins were carefully dissected.

\section{Observations:}

In the present study, variations in the draining pattern of azygos system of veins were observed in seven specimens. All the variations in the present study were observed in hemiazygos and accessory hemiazygos veins. No variation was observed in the formation and termination of azygos vein.Observations of the present study showed that most of the variations were due to persistence of left posterior cardinal vein and intermediate supracardinal vein. Among the seven specimens, six specimens showed variations in the drainage pattern of left posterior intercostal spaces i.e, mainly in the formation and termination accessory hemiazygos and hemiazygos veins. In one specimen, on the right side, $9^{\text {th }}$ and $10^{\text {th }}$ posterior intercostal artery passing infront of azygos vein few inches cranial to its formation. such variation was seldom reported. These seven different types of configuration are described as follows:

Variation: 1 In this specimen, $2^{\text {nd }}$ to $11^{\text {th }}$ Left posterior intercostal veins drained into single trunk (hemiazygos vein and accessory hemiazygos vein). This trunk terminated superiorly into left brachiocephalic vein and inferiorly joined the azygos vein at the level of $9^{\text {th }}$ thoracic vertebra. Prior to its termination into azygos vein this venous trunk received $9^{\text {th }}, 10^{\text {th }}$ and a twig from $8^{\text {th }}$ left posterior intercostal veins. The $11^{\text {th }}, 12^{\text {th }}$ and a twig from $10^{\text {th }}$ posterior intercostal vein (hemiazygos ) drained separately into azygos veins at T11 vertebral level (Fig2).

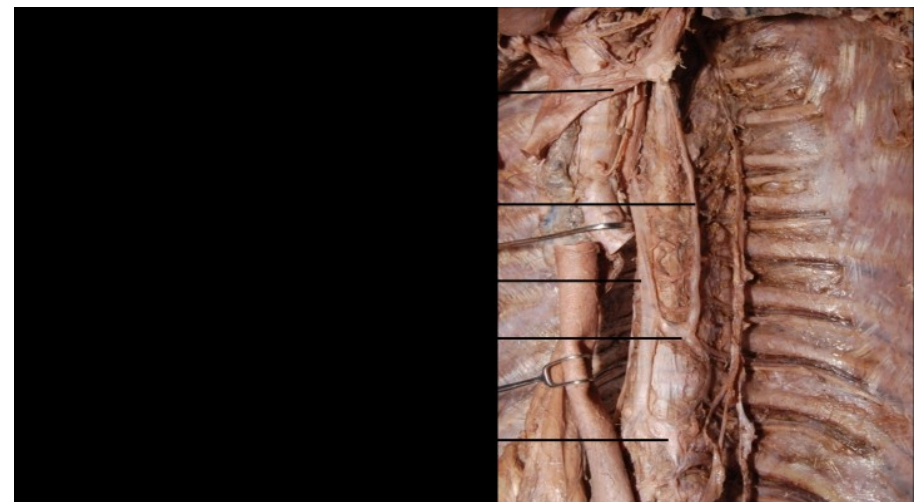

Fig 2: Hemiazygos vein and accessory hemiazygos vein forms common channel and drains into left brachiocephalic vein above and azygos vein below.

Variation: 2 In this specimen, the $2^{\text {nd }}$ to $6^{\text {th }}$ posterior intercostal veins of left side formed the accessory hemiazygos vein which drained into azygos vein at T5 level. The $7^{\text {th }}$ and $8^{\text {th }}$ left posterior intercostal veins united to form a single vein which drained into azygos vein at the level of $\mathrm{T} 7$ vertebra. The hemiazygos vein drained into azygos vein at the level T9 after receiving $9^{\text {th }}$ to $12^{\text {th }}$ intercostal veins (Fig3). 


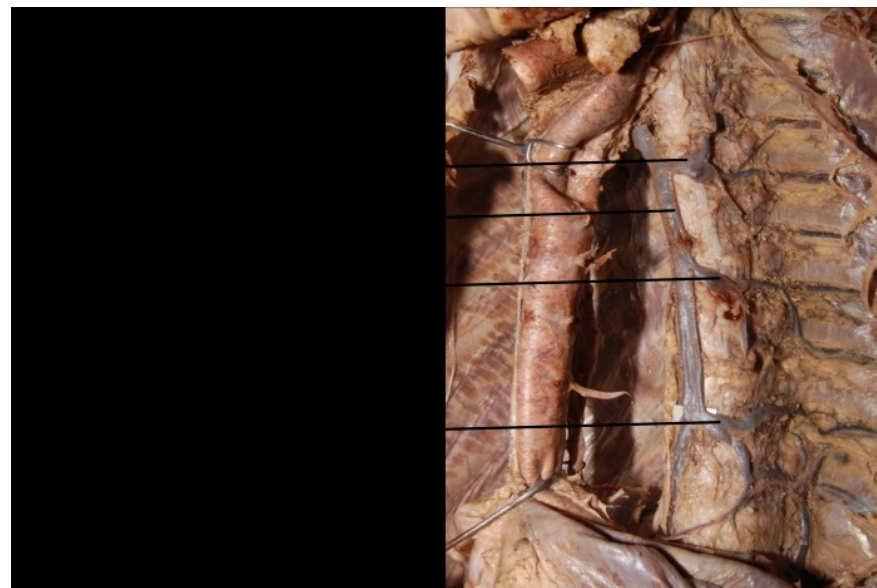

Fig 3: Variable drainage pattern of accessory hemiazygos vein with Left $7^{\text {th }}$ and $8^{\text {th }}$ posterior intercostal vein draining into azygos vein at $\mathbf{T} 7$ level.

Varaition: 3 Type $3^{\text {rd }}$ configuration was similar to that described in type- 1 configuration. A single venous trunk after receiving $2^{\text {nd }}$ to $11^{\text {th }}$ left posterior intercostal veins, drained by two routes into left brachiocephalic vein superiorly and azygos vein inferiorly at the level of T7 vertebra. The common channel before it terminated into left brachiocephalic vein also received pericardiophrenic vein. Hemiazygos vein followed the normal pattern of drainage after receiving $9^{\text {th }}$ to $11^{\text {th }}$ left posterior intercostal veins (Fig4).

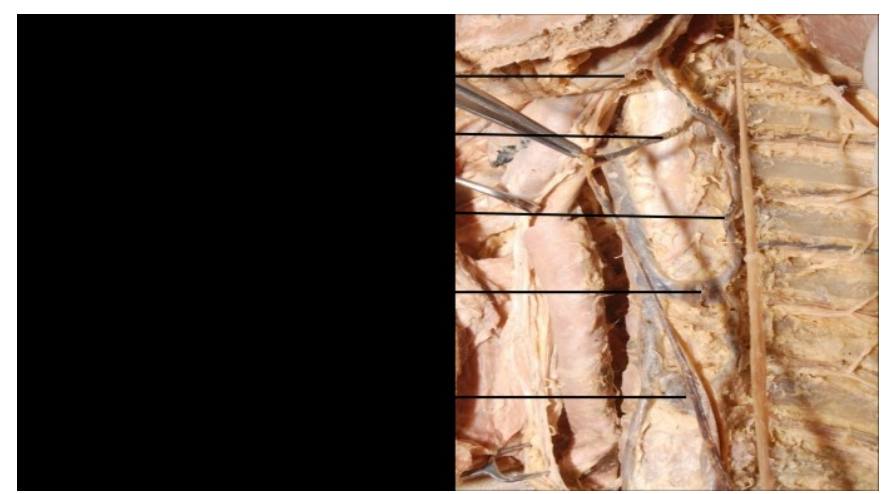

Fig 4: Accessory hemiazygos vein receives pericardiophrenic vein and drains into left brachiocephalic vein above and azygos vein below.

Variation:4 The accessory hemiazygos vein formed a single venous trunk after receiving $2^{\text {nd }}$ to $8^{\text {th }}$ left posterior intercostal veins. The termination of accessory hemiazygos vein occured in 3 ways. Superiorly it drained into left brachiocephalic vein and inferiorly into the azygos vein at the level of T7 vertebra. In the $3^{\text {rd }}$ way observed, it drained into azygos vein at the level of T6 vertebra.

Varaition: 5 In this type of configuration, the $1^{\text {st }}-7^{\text {th }}$ posterior intercostal veins from the left side formed a single venous channel which terminated into left brachiocephalic vein superiorly and azygos vein inferiorly at the level of $7^{\text {th }}$ thoracic vertebra. The $8^{\text {th }}$ left posterior intercostal vein joined the venous channel mentioned above prior to its termination into azygos vein. The $9^{\text {th }}$ left posterior intercostal vein drained separately into azygos vein at $\mathrm{T} 8$ level. The $10^{\text {th }}-12^{\text {th }}$ posterior intercostal veins formed hemiazygos vein which drained into azygos vein at the level of $10^{\text {th }}$ thoracicvertebra.

Variation: 5a Interestingly in the same specimen, the right $9^{\text {th }}$ and $10^{\text {th }}$ posterior intercostal arteries passed in front of azygos vein, instead of passing posterior to it.

Variation: 6 This type of variation was almost similar to that described in type-2 configuration. This type was observed in one specimen, the accessory hemiazygos vein after receiving $2^{\text {nd }}-8^{\text {th }}$ left posterior intercostal veins drained into left brachiocephalic vein above and azygos vein at the level of T5. The left $7^{\text {th }}$ posterior intercostal vein drained separately into azygos vein. The left $9^{\text {th }}$ posterior intercostal vein bifurcated and drained into two veins. One tributary passed above to join the $8^{\text {th }}$ posterior intercostal vein which drained separately into azygos vein, while the other tributary passed inferiorly to join the left $10^{\text {th }}$ posterior intercostal vein and drained into 
azygos vein. At the level of $9^{\text {th }}$ thoracic vertebrae, the $11^{\text {th }}$ and $12^{\text {th }}$ intercostal veins formed a single trunk and drained into azygos vein at T10 level.

Variation: 7 This type of configuration was almost same as that of normal drainage pattern of azygos system of veins. The only variation observed was the left $8^{\text {th }}$ posterior intercostal vein draining separately into azygos vein, whereas $5^{\text {th }}$ to $7^{\text {th }}$ posterior intercostal veins formed accessory hemiazygos vein and $9^{\text {th }}-11^{\text {th }}$ left posterior intercostal veins formed hemiazygos vein, as observed in the normal pattern (Fig5).

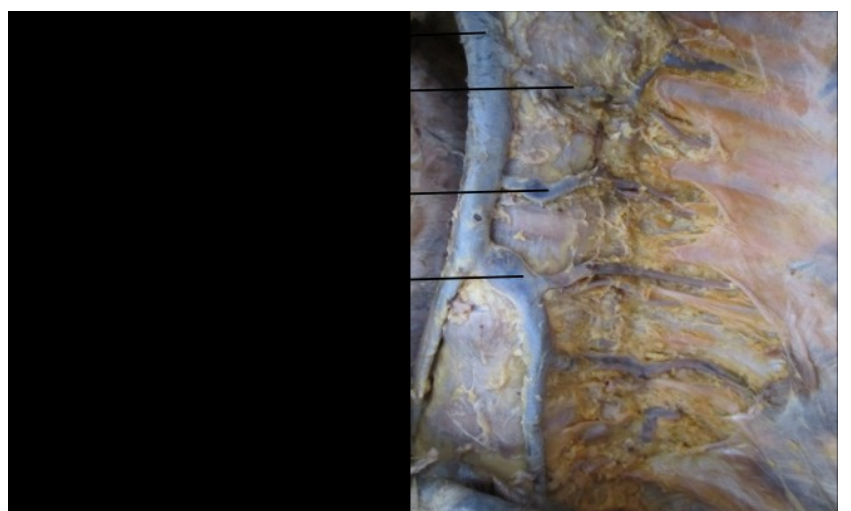

Fig 5: Left $8^{\text {th }}$ posterior intercostal vein separately draining into azygos vein

\section{Discussion}

Knowledge of development of azygos system of veins is necessary to understand the variations of azygos, hemiazygos and accessory hemiazygos veins. Azygos system of veins develop on the basis of various modifications occurring in subcardinal veins. Greater variability in the formation and drainage pattern of these veins are mainly due to the following reasons. Azygos vein is an important junction between venacaval and portocaval systems. It forms an important route of collateral circulation in venacaval occlusion such as in portal hypertension (Elzbieta Krakowiak-Sarnowska et al 2003). Based on previous reports on the azygos system of veins, it is proven that least variabilities were seen in azygos vein. Only 6 cases of absence of azygos vein have been reported. Whereas variations in hemiazygos vein have been reported $85.4 \%$ and accessory hemiazygos vein $80 \%$ of the cases (Arslan et al 2000 and Hatfield et al 1987).

In variation 1, the accessory hemiazygos vein was found to drain through two way communication, into left brachiocephalic vein above and azygos vein below. The hemiazygos vein apart from draining into azygos vein also sents a communicating twig to the trunk of accessory hemiazygos vein. The reason for such variatons is due to persistent left supracardinal vein and numerous anastomotic channels between two supracardinal veins during development. Bergman et al, (2008) reported incomplete formation of azygos and hemiazygos vein. Presence of double azygos vein is also reported in $15 \%$ of cases. This is due to persistence of two supracardinal veins (Coscina et al, 1986 and Necdet Kocabiyik et al, 2006).

As described in previous specimen the accessory hemiazygos vein draining into left brachiocephalic vein was also found in variation-3, 4, and 5. These type of variations are rarely reported (Manimay Bandyopadhyay 2010). Such venous communication forms an important channel for collateral circulation during obstruction. The accessory hemiazygos vein communicating with left brachiocephalic vein may be due to unobliterated left posterior cardinal vein. In addition, two way communication of accessory hemiazygos vein into left brachiocephalic vein above and azygos vein below were found in four specimens (variation-1,3,4 and 5). In the present study, the posterior intercostal veins involved in the formation of accessory hemiazygos vein was highly variable. In variation-1, the $2^{\text {nd }}$ to $8^{\text {th }}$ left posterior intercostal veins formed a two way drainage channel into the left brachiocephalic vein above and azygos vein below. In variation-3 it was observed that $2^{\text {nd }}$ to $11^{\text {th }}$ left posterior intercostal veins formed a common trunk (accessory hemiazygos vein), it received pericardiophrenic vein before draining into the two way channel. A similar variation was reported by (Kocabiyik et al, 2006) with accessory hemiazygos vein draining above T10 level. Variation-4 showed accessory hemiazygos vein receiving left $2^{\text {nd }}$ to $6^{\text {th }}$ posterior intercostal veins. Similar variation was reported by Mohato. NK et al, 2009. The upper left six intercostal spaces form a common channel of drainage in a two way communication. Variation-5 is as similar as variation-4, but the termination of accessory hemizygos vein into azygos vein was above left seven posterior intercostal spaces. Individual intercostal vein especially $7^{\text {th }}$ and $8^{\text {th }}$ left posterior intercostal veins and occasionally $9^{\text {th }}$ left posterior intercostal vein form a common trunk and drains into azygos vein. This venous channel passing ventral to the aorta, considered as interazygos vein is thought to originate during development from abnormal communication between left intersegmental veins and the right venous line (Pyrzowski.J et al, 
2007). Frequency of such pre-aortic connection is thought to be $2.5 \%$ ( Butler. $\mathrm{H}$ et al, 1952) and $3.6 \%$ (Seib GA. et al, 1934) and these veins are prone to severe bleeding during surgical manipulation.

Ozdemer et al, (2002) reported a case of preaortic interazygos vein, in which left $8^{\text {th, }} 9^{\text {th, }} 10^{\text {th }}$ and $11^{\text {th }}$ posterior intercostal veins drains into azygos vein independently. The left $4^{\text {th }}$ to $6^{\text {th }}$ posterior intercostal veins form superior trunk whereas $7^{\text {th }}$ and $8^{\text {th }}$ left posterior intercostal veins form inferior trunk. The above two channels unite to form a common trunk, and passes between aorta in front and oesophagus behind to drain into azygos vein at T4 level. Srijit das et al, (2004) reported a case of preaortic interazygos vein, in which left $4^{\text {th }}$ to $6^{\text {th }}$ posterior intercostal veins form accessory hemiazygos vein, $7^{\text {th }}$ and $8^{\text {th }}$ form single trunk whereas $8^{\text {th }}$ to $11^{\text {th }}$ posterior intercostal veins form hemiazygos vein. The above mentioned channels unite to form a common single trunk which crosses in front of descending thoracic aorta, before draining into azygos vein. The right $9^{\text {th }}$ and $10^{\text {th }}$ intercostal arteries passing anterior to azygos vein was observed in one specimen (variation-5). There is a strong possibility of compression of azygos vein during increased arterial pressure in these intercostal arteries. This may interfere with normal drainage of blood through azygos vein.

EMBRYOLOGICAL BASIS OF SUCH VARIATIONS Variations in the present study were observed mainly in drainage pattern of accessory hemiazygos vein and hemiazygos vein. Two way communication of accessory hemiazygos and hemiazygos vein draining into left brachiocephalic vein above and azygos vein below was found in variations-1,3,4, and 5 . This is due to persistence of parts of left posterior cardinal vein during development.The common single venous trunk found between accessory hemiazygos and hemiazygos vein is due to persistent additional anastamotic channels between left supracardinal vein and persistent intermediate supracardinal veins. Additional drainage channels for accessory hemiazygos and hemiazygos vein apart from draining into azygos vein is due to formation of more than two subcentral anastamosis between right and left supracardinal veins Failure of intermediate connections of left supracardinal veins may result in individual left posterior intercostal veins directly draining into azygos vein. Due to this, there is incomplete formation of accessory hemiazygos and hemiazygos veins. This type of variation was observed in four specimens.

\section{Conclusion}

Variations were mainly observed in drainage pattern of accessory hemizygos and hemiazygos vein. The accessory hemiazygos vein frequently drained through a two way communication in to brachiocephalic vein above and azgos vein below. Knowledge of drainage pattern of azygos system of veins is necessary. These anomalous drainage patterns may be misinterpreted as aneurysm, tumour and lymphadenopathy during radiological examination of posterior mediastinum. Cardiothoracic surgeons should be aware of such variations to prevent intrathoracic hemorrhage during operative procedures of posterior mediastinum. Azygos system of veins serve as an alternate drainage channel between inferior venacava and superior venacava in case of obstruction of its tributaries. Anomalous venous channels described in this study may serve as an effective alternate channel during superior and inferior venacaval obstruction. Aneurysm of the azygos veins are often asymtamatic and are usually incidently detected on a chest radiograph,if the aneurysm is very large it compress the right main bronchus (or) SVC.

\section{References}

[1]. Ainory P. Gesase, Flora M. Fabian, David N. Ngassapa. Double superior venacava presenting with anomalous jugular venous systems. Indian Heart Journal.1978; 1 - 10

[2]. Arslan G, Cebuk M, Ozkaynak C, Sindel T, Luleci E. Absences of the azygos vein. J clin imag. 2000; 24: 157-158.

[3]. Bergman.RA, Afifi.AK, and Miyauchi.R. Illustrated encyclopedia of human anatomic variation: opus ll: cardiovascular system: veins, head, neck, and thorax,12 edition. 1966.

[4]. Butler H, Balankura K. Preaortic throcic duct and azygos veins. J. Anat. Rec. 1952; 113: 409-419.

[5]. Constantin B. Marcu, Aernout M. Beek and albert C. Van Rossum. Unusual variation in upper body venous anatomy found with cardiovascular MRI. Canadian Medical Association Journal. 2006; 175(1), doi: 10.15039.

[6]. Coscina WF, Arger PH, Mintz MC, Coleman BG. Concurrent Sduplication and azygos continuation of the inferior venacava. J Comput Tomogr. 1986; 10: 287-290.

[7]. Datta AK. Essentials of human anatomy. $5^{\text {th }}$ edition, Current books international. 2000; 102-103.

[8]. Datta AK. Essentials of human embryology. $5^{\text {th }}$ edition, Current Books International. 2000; 197-212.

[9]. Elzbieta Krakowiak-Sarnowska et al. Variability of the azygos vein system in human foetuses. Via medica J. 2003; 62, No. 4, 427 430 .

[10]. Hamilton WJ, Mossman HW. Hamilton, Boyd and Mossman's Human embryology. $4^{\text {th }}$ Ed., London \& Basingstoke, The Macmillan press Ltd. 